\title{
Hepatitis viral en la gestación
}

\author{
Pío Iván Gómez Sánchez*
}

\begin{abstract}
RESUMEN: La primera causa de ictericia en el embarazo es la hepatitis viral que puede ser causada por lo menos por cinco virus (A, B, C, D y E). El descubrimiento del virus de la hepatitis C y Delta prácticamente eliminó las antes denominadas Hepatitis No A No B y aún existe la posibilidad de descubrir nuevos virus.

En este artículo se presenta un caso clínico de hepatitis B y se revisa etiología, diagnóstico, profilaxis y tratamiento de las diferentes hepatitis virales, haciendo énfasis en el diagnóstico, tratamiento y profilaxis del hijo de madre con hepatitis B, por la morbimortalidad que representa. Se revisa la hepatitis Delta, importante en Colombia, por tener zonas endémicas de este virus que requiere la infección previa o simultánea de hepatitis B. Por último se revisa la hepatitis $E$, de características similares a la hepatitis $A$, pero que afecta preferencialmente a la mujer gestante y en ella tiene mayor índice de morbimortalidad.
\end{abstract}

PALABRAS CLAVES: Hepatitis viral, gestación.

SUMMARY: The first cause of jaundice in gestation is viral hepatitis that can be caused by at least five virus (A, B, C, D and E). The discovery of the virus that produce hepatitis $C$ and hepatitis delta had made, before named hepatitis No $A$ No $B$ to be practically not mentioned and it is still believed that there is a posibility of finding other viruses.

In this article the etiology, diagnosis and management of the different known virus causing hepatitis are revised, making emphasis in hepatitis B, demostrating it with a clinical case; hepatitis delta whose virus requires the presence of infection by virus of previous or concomitant hepatitis $B$ and wich has special interest for having Colombia endemice zones with hepatitis delta; finally we will study hepatitis $\mathbf{E}$ that has characteristics similar to those of hepatitis $\mathbf{A}$, being able to infect with more frequency the pregnant woman and it is here where the major index of morbid-mortality is found.

KEY WORDS: Viral hepatitis, pregnancy.

\section{Introducción}

La hepatitis viral es la causa más común de ictericia durante el embarazo (40\%) (1-2).

Las embarazadas no son más susceptibles a la infección que las no embarazadas de la misma edad (3), a excepción de la hepatitis E.

El parto pretérmino es algo frecuente en estas pacientes, pero el bienestar del recién nacido depende del grado de madurez del mismo; no hay datos consistentes de que la hepatitis viral aumente la frecuencia de malformaciones congénitas (4).

La hepatitis viral puede ser causada por cuanto menos, cinco agentes diferentes: Hepatitis A, hepatitis B, hepatitis $C$, hepatitis delta y hepatitis $E$ y con perspectivas de aumentar este creciente abecedario de hepatitis. El cuadro clínico en la paciente sintomática es similar en todas y se caracteriza por un pródromo en el cual hay náuseas, vómito, anorexia, fatiga y fiebre de poca intensidad; síntomas que pueden durar desde pocos días a pocas semanas, apareciendo posteriormente ictericia, coluria y acolia.

Profesor Asociado. Departamento de Ginecología y Obstetricia. Universidad Nacional de Colombia.

\section{Reporte de un caso}

Paciente de 25 años que consulta médico particular por presentar náusea, anorexia, malestar general de 6 días de evolución. Antecedentes familiares y personales patológicos sin importancia. Antecedentes quirúrgicos: septorrinoplastia hace 2 años; gestación ectópica tratada con salpinguectomía izquierda hace 1 año, requiriendo transfusión.

Antecedentes Gineco-Obstétricos: Menarquia: 14 años ciclos regulares $30 \times 3$. G4P1A1E1. FUR: Enero 121994.

$E F$ : Paciente consciente, levemente deshidratada, tinte ictérico mucocutáneo. TA: 110/75 FC: 89 FR: 16.

Cardiopulmonar: sin alteraciones. Abdomen: Ruidos intestinales presentes, abdomen blando depresible, no doloroso, no signos de irritación peritoneal. Altura uterina: $21 \mathrm{cms}$.

Fetocardia: Doppler (160 x minuto)

Examen genital: cuello posterior cerrado, no sangrado genital.

Conducta: Se realiza impresión diagnóstica de Síndrome ictérico en estudio y gestación de 24 semanas. Se hospitaliza, se hidrata, se inicia metoclopramida IV y se solicitan laboratorios.

Laboratorios: Cuadro hemático: $\mathrm{Hb}: 14,3 \mathrm{gm} / 100 \mathrm{ml}$ Hcto: 45. 
Leucocitos: 6800, PMN: $40 \%$ Linf: $52 \%$ Eo: 2 Monoc:

6. VSG: 25 .

Bilirrubinas totales: $18.2 \mathrm{mgr} / 100 \mathrm{ml}$. Directa: 8.8 $\mathrm{mg} / 100 \mathrm{ml}$, Indirecta: $9.4 \mathrm{mg} / \mathrm{ml}$.

SGOT: $880 \mathrm{UI} / \mathrm{ml}$, SGPT: $1030 \mathrm{ui} / \mathrm{ml}$. Fosfatasa Alcalina: $20 \mathrm{U}$.

Glicemia: $85 \mathrm{mgr} / 100 \mathrm{ml}$. Triglicéridos: $156 \mathrm{mg} / 100 \mathrm{ml}$.

Colesterol: $220 \mathrm{mg} / 100 \mathrm{ml}$. Creatinina: $0.7 \mathrm{mg} / 100$ ml. DHL: $200 \mathrm{U} / \mathrm{ml}$.

Parcial de Orina: sin evidencia de infección, leve proteinuria, presencia de urobilinógeno y cilindros granulosos.

Se hace diagnóstico de Hepatitis viral y se solicita perfil inmunológico hepatitis $\mathrm{A}, \mathrm{B}, \mathrm{C}$, encontrándose:

Hepatitis A Antic. Totales (Elisa): negativos.

Antígeno de superficie HBsAg (Elisa): Positivo.

Anticuerpos totales antihepatitis C (FIA-MEIA): Negativos.

Se hace diagnóstico de hepatitis B aguda, se hace manejo sintomático. Se toma muestra para Anticuerpos totales antihepatitis Delta (metodología FIA-MEIA) que se reportan como negativos. Se da de alta a los 5 días de hospitalización y se continúa control prenatal sin complicaciones.

Parto eutósico el día 10 de octubre de 1994, sin complicaciones obteniendo fruto de la gestación sexo femenino; Peso: $2.850 \mathrm{gr}$.

Apgar: $8 / 10$ al minuto y $10 / 10$ a los 5 minutos. Se inicia a las 10 horas de nacido profilaxis para hepatitis $B$ así: inmunoglobulina de hepatitis $\mathrm{B}, 0.5 \mathrm{ml}$ y vacuna para hepatitis B: 10 microgramos, ambas vía Intramuscular. Madre e hijo se dan de alta 36 horas después del parto.

Control por pediatría del neonato al mes y seis meses no muestra alteraciones y se aplica en estos mismos, refuerzo de vacuna de hepatitis B. Se titula Antígeno de superficie a los 9 meses el cual es negativo y anticuerpos contra antígeno de superficie: $50 \mathrm{mUI} / \mathrm{ml}$, mostrando efectividad de profilaxis. Queda pendiente nuevo control de Antígeno de superficie y anticuerpos.

\section{Discusión}

En el diagnóstico de hepatitis la anormalidad bioquímica más característica es el aumento de las aminotransferasas.

Debemos tener en cuenta que algunos casos pueden ser anictéricos con sintomatología leve y con aminotransferasas no muy elevadas, por ende debemos tener la hepatitis viral presente como diagnóstico en aquellas pacientes con anormalidades moderadas de las pruebas de función hepática durante la gestación (5).

Teniendo como base el caso descrito, insistamos que la primera causa de ictericia en la gestación sigue siendo la hepatitis viral, pero actualmente no podemos estar tranquilos por el solo hecho de tener una paciente con sintomatología leve y se hace necesario usar los medios disponibles para hacer un diagnóstico exacto del tipo de virus causante, ya que las implicaciones sobre el binomio madre-feto son diferentes para cada una de las siguientes entidades que brevemente describiremos, enfatizando en la etiopatogenia, clínica, profilaxis y tratamiento.

\section{Hepatitis A}

El causante es un virus ARN con un tamaño de $27 \mathrm{~nm}$ (6), de transmisión fecal-oral y con período de incubación corto, de aproximadamente 15-49 días. El diagnóstico de hepatitis $\mathrm{A}$ se hace clínicamente y por la presencia de anticuerpos IgM (anti-VHA) en el suero (6); esta prueba es positiva prácticamente en todas las pacientes enfermas. Los anticuerpos IgG anti-VHA también se forman en las pacientes enfermas y permanecen por tiempo indefinido.

Se han reportado partos prematuros, pero en general el pronóstico materno fetal es muy bueno, no hay estado de portador ni hepatitis crónica; es una enfermedad muy común, calculándose que el $80 \%$ de las personas mayores de 50 años tienen datos serológicos de infección previa.

\section{Hepatitis B}

Su causante es un virus ADN con un tamaño de $24 \mathrm{~nm}$ y su transmisión es básicamente de trasmisión sexual y mediante suero infectado, con período de incubación más largo (de 28-160 días), de comienzo más insidioso que la hepatitis $\mathrm{A}$. Su evolución es a menudo más prolongada y grave que en la hepatitis A; las bilirrubinas y aminotransferasas suelen estar más altas, sin embargo muchas pacientes son anictéricas. En general suele ser más grave que la hepatitis A por sus secuelas clínicas crónicas y porque es frecuente el estado de portador crónico. Esta enfermedad es mundial pero se ha considerado endémica en Africa y Asia donde se le atribuye la alta incidencia de hepatomas (7).

Poco después de la transmisión del virus de la hepatitis B intacto (denominado partícula DANE), se produce la infección hepática. El genoma viral se incorpora en el núcleo, se inicia la producción del centro viral dentro del núcleo y de la túnica viral en el citoplasma; estos dos materiales se funden para formar la partícula viral y se secretan de la célula como forma infectante. El material de la túnica viral se suele producir en gran cantidad y se detecta en el suero como antígeno de superficie $\left(\mathrm{HB}_{\mathrm{s}} \mathrm{Ag}\right)$ midiendo $17-25 \mathrm{~nm}$, el cual no es infeccioso pero es muy útil como marcador de infección, pues aparece 10-14 días antes de que haya sintomatología. La partícula DANE aparece igualmente en este período pero ni el virus intacto ni el antígeno central tienen utilidad clínica para la infección aguda, mientras que el antígeno "e" $\left(\mathrm{HB}_{\mathrm{e}} \mathrm{Ag}\right)$ que se encuentra íntimamente emparentado con la partícula DANE suele existir en esta fase incipiente, usándose como indicador indirecto de la presencia de partículas virales completas y por lo tanto del estado infeccioso. El $\mathrm{HB}_{\mathrm{e}} \mathrm{Ag}$ generalmente desaparece a las 6-8 semanas del comienzo clínico de la enfermedad y su presencia por más de 3 meses se asocia muchas veces con hepatitis crónica (7).

El anticuerpo contra antígeno "e" aparece en el momento en que culminan los síntomas clínicos y persiste por varios años. El anticuerpo contra antígeno de superficie aparece tarde en la fase de recuperación de la hepatitis B y persiste varios años (7).

El diagnóstico de la enfermedad se hace por las características clínicas y se confirma por las alteraciones inmunológicas. 
En cuanto a sintomatología referíamos ya su similitud con la hepatitis A, salvo que el pródromo es más prolongado e insidioso, acompañándose a menudo de altralgias, artritis franca y erupción cutánea; también se ha mencionado glomerulonefritis en adultos y niños con esta enfermedad. En poblaciones donde hay extremada desnutrición su asociación con embarazo trae gran riego de hepatitis fulminante.

En cuanto al diagnóstico por alteraciones inmunológicas hay gran variabilidad ya que en algunos casos pueden existir simultáneamente todos los marcadores inmunológicos, o puede haber una ventana inmunológica. La persistencia de $\mathrm{HB}_{\mathrm{s}} \mathrm{Ag}$ y la no aparición de anticuerpos contra HB Ag es característico del estado de portador en un $10 \%$ de los pacientes. De los portadores el $50 \%$ tienen manifestaciones de hepatitis persistente crónica o activa crónica, asociándose la hepatitis activa crónica con cirrosis postnecrótica y hepatoma, al igual que muerte, sin embargo hay pacientes con hepatitis activa crónica en capacidad de concebir que acarrean problemas como insuficiencia hepática, várices esofágicas sangrantes, prematurez y potencial de transmisión vertical de hepatitis $\mathrm{B}$ al recién nacido (8).

La ocurrencia de hepatitis B en el primer o segundo trimestre del embarazo no trae mayor riesgo, mientras que su ocurrencia en el tercer trimestre se asocia con riesgo de prematurez y mayor mortalidad fetal (9).

La infección perinatal se supone causada por la exposición bucal del neonato a la sangre y/o heces fecales infectadas durante el parto, pero la transmisión puede ocurrir durante los cuidados postparto a partir de la madre o de otros miembros de la familia infectados (610). La transmisión transplacentaria ocurre sólo en el $5 \%$ de los casos y se ha incriminado también transmisión por calostro (11).

La mayoría de los lactantes son asintomáticos y se convierten en portadores crónicos con riesgo posterior de adquisición de hepatoma (12), otros adquieren hepatitis aguda, enfermedad fulminante y/o cirrosis, pudiendo fallecer.

En cuanto a la transmisión vertical, la frecuencia de portadores crónicos de $\mathrm{HB}_{\mathrm{s}} \mathrm{Ag}$ varía, siendo menor de $1 \%$ en países occidentales pero en Asia o Africa puede llegar al $40 \%$. El riesgo de transmisión varía igualmente, siendo cercano al $70 \%$ en Asia, $15 \%$ en USA y menor del $1 \%$ en Escandinavia (13-15).

Estas variaciones dependen de muchos factores, pero uno determinante es el $\mathrm{HB}_{\mathrm{e}} \mathrm{Ag}$ en la madre, pues se halla íntimamente ligado con la cantidad de partículas DANE circulantes. Las madres con este antígeno positivo y con presencia de $\mathrm{HB}_{\mathrm{s}} \mathrm{Ag}$, transmiten hepatitis a sus hijos hasta en un $95 \%$ (16), mientras las que tienen antígeno "e" negativo y anticuerpo "e" positivo no transmiten la infección.

\section{Hepatitis C, Hepatitis Delta y Hepatitis E}

En 1989 se muestra la secuencia genética del virus de la hepatitis $\mathrm{C}$, el cual es el causante de la mayoría de las antes denominadas hepatitis No A No B; de transmisión parenteral y puede ser causante tanto de hepatitis aguda, hepatitis crónica, activa y cirrosis como de carcinoma hepatocelular (17).

La hepatitis delta ocurre en forma endémica en grupos de portadores crónicos de antígeno de superficie de hepatitis $\mathrm{B}\left(\mathrm{HB}_{\mathrm{s}} \mathrm{Ag}\right)$ en algunas regiones como Medio Oriente y Mediterráneo, en colonias aisladas de indígenas en la Amazonia, entre los indios Yucpa de Venezuela y entre pobladores mestizos de la Sierra Nevada de Santa Marta en nuestro país, siendo de mayor frecuencia en pacientes politransfundidos y drogadictos parenterales.

El virus de la Hepatitis Delta (VHD) es un Virus ARN que no se puede replicar sino con la ayuda facilitadora del $\mathrm{HB}_{\mathrm{s}} \mathrm{Ag}$, por ende se necesita que el individuo sea portador de $\mathrm{HB}_{\mathrm{s}} \mathrm{Ag}$ o que tenga hepatitis crónica por Virus B. Puede aparecer como superinfección en el portador crónico de $\mathrm{HB}_{\mathrm{s}} \mathrm{Ag}$ con Hepatitis $\mathrm{B}$ crónica, pero también puede aparecer en forma de cooinfección cuando se presenta simultáneamente con una hepatitis B aguda.

En cualquiera de los casos se presenta una hepatitis aguda severa con mortalidad de $2 \%-20 \%$ y tiene una incidencia de progresión a cirrosis del $70-80 \%$, por lo que se considera un proceso mucho más severo que la hepatitis B aislada.

El diagnóstico puede hacerse determinando el anticuerpo contra VHD por Radio-inmunoanálisis; recientemente se han descrito técnicas para medir antígeno VHD (Western Blot) y para medir ARN del VHD (Hibridación molecular) (18-19).

A comienzos de 1990, investigadores norteamericanos, encabezados por el Dr. Gregory Reyes obtienen la clonación o copia molecular del genoma viral de la hepatitis E que consiste en un Virus ARN simple sin envoltura, de transmisión Fecal-Oral con una característica clínica que le confiere gravedad especial y es que ocurre con predilección en mujeres gestantes, oscilando la mortalidad entre 20 y $39 \%$ (20).

\section{Tratamiento de Hepatitis en la Gestación}

El tratamiento de la hepatitis viral en las pacientes embarazadas es semejante al de la paciente no embarazada; deben recibir una dieta balanceada, insistiendo en la ingestión adecuada de proteínas; en hepatitis no complicada no hay bases para hacer restricción proteica ni proporcionar cantidades excesivas de carbohidratos; deben tener reposo adecuado y obviar los medicamentos que no sean absolutamente necesarios por su toxicidad potencial sobre el hígado.

En las hepatitis A se deben tener técnicas de aislamiento entérico hasta cuando ocurran la ictericia y la elevación de las aminotransferasas; en la hepatitis B no es necesario. Solamente tener cuidados con elementos punzantes como agujas y recomendar abstinencia sexual o el uso cuidadoso de métodos de barrera combinados (condón y espermicidas).

En pacientes con hepatitis A, se deben buscar los contactos y se puede colocar globulina sérica inmune a dosis de $0.06 \mathrm{ml} / \mathrm{Kg}$ de peso con efectividad cercana al $80 \%$ si se coloca dentro de las primeras 2 semanas del contacto.

En hepatitis B si hay contactos de alto riesgo se debe colocar globulina inmunitaria para la hepatitis B $(0.06$ 
$\mathrm{ml} / \mathrm{Kg}$ mensual por dos meses); igualmente está indicada en zonas endémicas al igual que como profilaxis en pacientes usuarias de diálisis. En ausencia de esta globulina inmunitaria se puede usar globulina sérica inmune a razón de $0.15 \mathrm{ml} / \mathrm{Kg}$ (7).

Los recién nacidos hijos de madres $\mathrm{HB}$ Ag positivo, deben recibir inmunoglobulina de hepatitis $\mathrm{B}(0.5 \mathrm{ml} \mathrm{IM})$ en las primeras 12 horas de nacidos ya que su eficacia disminuye grandemente cuando se retrasa su aplicación por más de 48 horas. Estos lactantes deben recibir vacuna para hepatitis $B, 0.5 \mathrm{ml}$ (10 microgramos) IM, preferiblemente en el momento de recibir la inmunoglobulina de hepatitis $B$ pero si no se puede por lo menos dentro de los primeros 7 días de nacido, teniendo en cuenta que no se interfieren entre sí, ni con cualquier otra vacuna (7).

Se deben reforzar las vacunas de hepatitis B al mes y seis meses de edad; este régimen es efectivo para prevenir la infección neonatal en cerca del 90\%. Se deben tomar muestras para $\mathrm{HB}_{\mathrm{s}} \mathrm{Ag}$ y anticuerpo para $\mathrm{HB}_{\mathrm{s}} \mathrm{Ag}$ a los 10-15 meses para evaluar el efecto de la profilaxis; si hay anticuerpos anti $\mathrm{HB}_{\mathrm{s}} \mathrm{Ag}$, indica inmunidad pero la presencia de $\mathrm{HB}_{\mathrm{s}} \mathrm{Ag}$ sugiere un estado de portador crónico o alguna forma de hepatitis $\mathrm{B}$ aguda o crónica.

En hepatitis Delta, lo mejor es la profilaxis para hepatitis B; se ha usado interferon alfa y en casos fulminantes transplante hepático. Experimentalmente se ha investigado el fosfonoformato bisódico (7).

\section{Conclusión}

La hepatitis viral en la gestación es el primer diagnóstico que debemos tener en mente en la paciente con ictericia y aunque no es causante de malformaciones si puede tener una alta morbimortalidad tanto de la madre como del neonato. Cualquier manifestación gastrointestinal en la gestación no debe subvalorarse y deben descartarse entidades como las antes mencionadas y especialmente en el último trimestre de la gestación tener en cuenta otras, como el hígado graso agudo de la gestación, síndrome Hellp y colestasis gestacional, que comparten características clínicas con las hepatitis virales pero su comportamiento e implicaciones para el binomio materno-fetal son diferentes.

\section{BIBLIOGRAFIA}

1. Miller JP. Enfermedades del hígado y aparato digestivo. Clínicas de Ginecol. y Obstet. Temas Actuales 1977; 4: 297.

2. Pritchard J., Macdonald P., Gant N. Obstetricia de Williams, 3a. Edición Salvat Editores S.A. 1987; 598.

3. Haemmerli UP. Jaundice during pregnancy, with especial emphasis on recurrent jaundice during pregnancy and its differential diagnosis. Acta Med. Scand. 1966; 179 (Suppl. 444): 1.

4. Scherlock S. Jaundice in pregnancy. Br. Med. Bull. 1967; 24: 39.

5. Yip D., Baker A. Medical disorders during pregnancy. 1985; 12:3-376.

6. Wand FR. Viral hepatitis and its effect on pregnancy. Clin. Obstet. Gynec. 1979; 22: 301 .

7. Gómez PI. Síndrome Ictérico en el embarazo. Memorias Curso Complicaciones Médicas en el Embarazo. Universidad Nacional de Colombia. 1988; 97-108.

8. Krejs GJ., Haemmerli UP. Miscellaneous disorders. Part. I. Jaundice during pregnancy. In Schiff L. and Schiff ER. (Eds); diseases of the liver. 5 th Ed. Philadelphia J B Lippincott Company, 1982.

9. Hieber JP., Dalton D. Hepatitis and pregnancy. J. Pediatr. 1977; $91: 45$.

10. Tong MJ., Thursby M., Rakela J et al. Studies on the maternal infants transmision of the viruses wich causes acute hepatitis. Gastroenterology. 1981; 80: 999.
11. Inmunization practices Advisory Commitee, Centers for disease control. Postexposure prophylaxis of hepatitis B. Recommendatios of the inmunization practices advisory commitee. Ann. Intern. Med. 1984; 101: 351.

12. Schweitzer L., Dunn A. Viral hepatitis B in neonates and infants. Am. J. Med. 1973; 55: 762.

13. Derson A., Boxall E. Transmission of $\mathrm{HB} \mathrm{Ag}$ from mother to infant in four ethnic groups. Br. Med. J. 1978; 1: 949.

14. Lee AK., Wong VC. Mechanisms of maternal fetal transmision of hepatitis B virus. J. Infect. Dis. 1978; 138: 668.

15. Stevens CE. Viral hepatitis in pregnancy: The Obstetrician's role Clin. Obstet. Gynecol. 1982; 25: 577.

16. Fallon HJ. Enfermedades Hepáticas en Burrow GN y Ferris TF. Complicaciones Médicas durante el embarazo. 1984;311, Saunders Philadelphia.

17. Hepatitis C. N. Engl. J. of Med. 1989; 317: 242-245.

18. Sotto A., Rodríguez N. Prevalencia del anticuerpo Delta en Cuba. Instituto de Gasteroenterología, Habana, Cuba. Presentado en el XXI Congreso Panamericano de Gastroenterología. Cartagena-Colombia. Sept. 1989.

19. Delta Hepatitis. Jama 1989; 261: 1321-1325.

20. Reyes G. Hepatitis E virus. Science 1990; 248: 1230-1234. 